ISSN : $2302-1590$

E-ISSN : $2460-190 X$

ECONOMICA

Journal of Economic and Economic Education Vol.2 No.1 (59- 66)

\title{
PENGARUH LATAR BELAKANG PENDIDIKAN DAN PELATIHAN TERHADAP KINERJA ACCOUNT OFFICER (AO) KREDIT KOMERSIAL BANK BRI SUMATERA BARAT
}

\author{
Ega Sri Dini \\ Mahasiswa Program Studi Pendidikan Ekonomi STKIP- PGRI Sumbar \\ Jl. Gunung Pangilun No.1, Padang Sumatera Barat \\ Email: desriwahyuni@yahoo.com \\ Mareta Kemala Sari \\ Dosen Program Studi Pendidikan Ekonomi STKIP- PGRI Sumbar \\ Jl. Gunung Pangilun No.1, Padang Sumatera Barat \\ Email: cha.delly@yahoo.com \\ Submited: 2013.08.21 Reviewed:2013.09.14 Accepted: 2013.10.13 \\ http://dx.doi.org/10.22202/economica.2013.v2.i1.21
}

\begin{abstract}
This study aims to reveal the effect of: educational background and training of employees kierja account officer (AO) BRI Bank of West Sumatra.Type of research conducted in this research is descriptive quantitative. The population is the total number of employees accounts officer (AO) Bank BRI Sumatra were 30. Sampling technique in this research is to use the total sampling where respondents were less than 100 then all the population sampled. Data were collected through a questionnaire using a Likert scale that has been tested validity and reliability. The data analysis technique used is descriptive analysis. To test the hypothesis used test and $f$. Based on the results of t-test of hypothesis testing is not educational background and significant positive effect on employee performance, training t-test positive and significant impact on employee performance. While testing the influence of $f$ together positive and significant correlation between educational background and pelaihan on employee performance. The amount of influence the educational background and training on employee performance is $32.90 \%$ and the remaining $67.10 \%$ is influenced by other variables not included in the research model.
\end{abstract}

Penelitian ini bertujuan untuk mengungkapkan pengaruh: latar belakang pendidikan dan pelatihan terhadap kierja karyawan account officer (AO) Bank BRI Sumatera Barat. Jenis penelitian yang dilakukan dalam penelitian ini adalah Deskriptif Kuantitatif. Populasi dalam penelitian ini adalah jumlah keseluruhan karyawan account officer (AO) Bank BRI Sumatera berjumlah 30 orang. Teknik pengambilan sampel dalam penelitian ini adalah menggunakan total sampling dimana responden yang kurang dari 100 maka semua populasi dijadikan sampel. Data dikumpulkan melalui angket dengan menggunakan skala likert yang telah diuji kesahihan dan kehandalannya. Teknik analisis data yang digunakan adalah analisis deskriptif. Untuk pengujian hipotesis digunakan uji $t$ dan uji $f$. Berdasarkan hasil pengujian hipotesis uji $t$ latar belakang pendidikan tidak berpengaruh positif dan signifikan terhadap kinerja karyawan, uji t pelatihan berpengaruh positif dan signifikan terhadap kinerja karyawan. Sedangkan uji $f$ pengaruh bersama-sama positif dan signifikan antara latar belakang pendidikan dan pelaihan terhadap kinerja karyawan. Besarnya pengaruh latar belakang pendidikan dan pelatihan terhadap kinerja karyawan adalah 32,90\% dan sisanya sebesar 67,10\% dipengaruhi oleh variabel lain yang tidak termasuk kedalam model penelitian.

Keywords: Educational Background, Training and Employee Performance 


\section{PENDAHULUAN}

Perusahaan, baik milik negara maupun swasta sebagai suatu perilaku ekonomi yang tidak lepas dari kondisi globalisas. Era globalisasi yang sedang berkembang saat ini memiliki suatu dampak dalam suatu persaingan dunia termasuk dalam dunia bisnis. Sebagai konsekuensi logis dari timbulnya persaingan yang semakin tajam, ada tiga kemungkinan yaitu, mundur, bertahan atau tetap unggul dan bahkan semakin berkembang. Kebijakan yang ditempuh manajemen antara lain meningkatkan pengawasan dalam kredit komersial.

Sebagaimana diketahui bahwa definisi kredit komersial yang dikemukakan oleh KDPK (Kebijakan dan Prosedur Kredit) adalah pemberian pinjaman kepada debitur atau nasabah dengan berbagai fasilitas baik kredit baru, tambahan maupun perpanjangan yang telah disediakan sesuai dengan kebutuhan debitur dengan persyaratan-persyaratan yang telah ditetapkan oleh bank.

Dengan demikian pemberian kredit komersial, bank harus melakukan pemeriksaan berkas-berkas dan melakukan survei kepada calon nasabahnya. Sehingga pihak bank harus berhati-hati dalam memberikan keputusan untuk mensahkan berkas-berkas pengkreditan komersial.

Pemberian kredit komersial ditangani oleh account officer (AO) mulai dari pemberian kredit hingga pemberian kredit itu selesei. Menurut Bank BRI, account officer (AO) merupakan karyawan yang bertugas untuk mencari nasabah yang layak sesuai dengan kriteria peraturan bank, menilai, mengevaluasi, mengusulkan besarnya kredit yang diberikan dalam mendapatkan seorang account officer (AO) yang diperlukan pendidikan yang memadai, agar bisa mengenali usaha yang layak dibiayai.

Pada Bank BRI, untuk dapat menumbuhkan kinerja dikalangan karyawan account officer (AO) tidak lepas dari latar belakang pendidikan yang menjadi peran penting didalamnya. Pelatihan yang dapat memotivasi karyawan agar dapat memahami serta mendapatkan hasil kinerja yang baik dan dengan adanya pelatihan, karyawan dapat berkomunikasi dengan sesama karyawan untuk membagi pengalaman dalam bekerja.

Oleh karena itu, seorang account officer (AO) tidak hanya berpendidikan ekonomi namun memiliki beragam pendidikan yang berbeda. Bank BRI sendiri memiliki beragam tenaga account officer (AO) dari beragam pendidikan. Hal ini dapat dilihat pada tabel 1 .

Seorang account officer (AO) harusnya dapat menarik calon nasabah dengan menggunakan cara yang bisa memenuhi kepuasan calon nasabah. Untuk memenuhi kepuasan nasabah itu sendiri, pihak bank memiliki 2 (dua) strategi yang dapat memenuhi kepuasan nasabah (Bahan ajar Account Officer 2009) yaitu:

1. Strategi menyerang

Yaitu bersikap agresif dalam menjerat calon nasabah, agresif disini maksudnya adalah memiliki persiapan menyerang yang matang dan cukup kuat untuk menyerang dengan cara menerapkan melakukan promosi yang menerangkan bahwa Bank BRI memiliki fasilitas pelayanan yang baik.

2. Strategi bertahan

Yaitu mempertahankan suatu promosi yang sudah ada dan berusaha menambah atau meningkatkan fasilitas pelayanan yang baik. Sehingga calon nasabah dapat mempercayai pihak bank untuk melakukan suatu kredit.

Manfaat pelatihan pada Bank BRI Sumatera Barat adalah :

a. Meningkatkan pengetahuan dan keterampilan 
b. Meningkatkan rasa percaya diri

c. Meningkatkan kepuasan kerja

d. Meningkatkan produktifitas
Dapat penulis simpulkan bahwa dengan adanya latar belakang pendidikan

Tabel 1. Data Account Officer (AO) Kredit Komersial

\begin{tabular}{|c|c|c|c|c|}
\hline NO & КАВ / KOTA & $\begin{array}{l}\text { LATAR BELAKANG } \\
\text { PENDIDIKAN }\end{array}$ & $\begin{array}{c}\text { JUMLAH } \\
\text { Karyawan } \\
\text { Account Officer } \\
\text { (AO) }\end{array}$ & $\begin{array}{l}\text { RATA-RATA } \\
\text { BEKERJA }\end{array}$ \\
\hline \multirow[t]{5}{*}{1.} & \multirow[t]{4}{*}{ Bukittinggi } & S. Teknik & 1 & 4 Tahun \\
\hline & & S. Komputer & 1 & 11 Tahun \\
\hline & & S. Hukum & 2 & 11-13 Tahun \\
\hline & & S. Ekonomi & 6 & 2-20 Tahun \\
\hline & \multicolumn{2}{|c|}{ TOTAL } & 10 & \\
\hline \multirow[t]{3}{*}{2.} & \multirow[t]{2}{*}{ Solok } & S. Teknik & 2 & 3-5 Tahun \\
\hline & & S. Ekonomi & 3 & 41-12 Tahun \\
\hline & \multicolumn{2}{|c|}{ TOTAL } & 5 & \\
\hline \multirow[t]{4}{*}{3.} & \multirow[t]{3}{*}{ Padang } & S. Komputer & 1 & 4 Tahun \\
\hline & & S. Hukum & 2 & 3-17 Tahun \\
\hline & & S. Ekonomi & 2 & 8 Tahun \\
\hline & \multicolumn{2}{|c|}{ TOTAL } & 5 & \\
\hline \multirow[t]{5}{*}{4.} & \multirow[t]{5}{*}{ Sijunjung } & S. Hukum & 1 & 4 Tahun \\
\hline & & S. Komputer & 1 & 15 Tahun \\
\hline & & S. Teknik & 1 & 3 Tahun \\
\hline & & S. Ekonomi & 2 & 4-10 Tahun \\
\hline & & $\mathbf{A L}$ & 5 & \\
\hline \multirow[t]{6}{*}{5.} & \multirow[t]{4}{*}{ Pariaman } & S. Sains & 1 & 3 Tahun \\
\hline & & S. Hukum & 2 & 5-13 Tahun \\
\hline & & S. Sosial & 1 & 3 Tahun \\
\hline & & S. Ekonomi & 1 & 5 Tahun \\
\hline & \multirow{2}{*}{\multicolumn{2}{|c|}{$\begin{array}{c}\text { TOTAL } \\
\text { TOTAL KESELURUHAN }\end{array}$}} & 5 & \\
\hline & & & 30 & \\
\hline
\end{tabular}

\section{Sumber: Bank BRI Sumatera Barat 2009}

seorang account officer (AO) baik berpendidikan ekonomi maupun non ekonomi akan mendapatkan suatu pelatihan yang diberikan oleh pihak Bank BRI, dengan itu pihak Bank BRI dapat menerima atau menolak account officer (AO) untuk dilibatkan dalam organisasi tersebut. Tentu dengan adanya kinerja yang bagus dan dapat menarik calon nasabah.

\section{Pendidikan}

Menurut Zainun dalam Sukoco (2010:76), pendidikan adalah untuk mempersiapkan SDM sebelum memasuki pasar kerja. Dengan pengetahuan yang diperolehnya dari pendidikan yang diharapkan sesuai dengan syarat-syarat yang dituntut oleh suatu pekerjaan.
Sedangan Sedarmayanti (2007:379) dalam Dienul Ihsan (2008) berpendapat bahwa pendidikan adalah suatu proses, teknik, dan metode belajar mengajar dengan maksud mentrasfer suatu pengetahuan diri seseorang kepada orang lain melalui prosedur yang sistematis dan terorganisir.

Pendidikan merupakan perkara penting dalam membangun sebuah negeri, rusaknya pendidikan akan melahirkan generasi yang rusak pula. Maka cara seseorang berbicara maupun cara mereka bersikap sesuai dengan pendidikan yang telah mereka miliki, jika mereka terlahir di daerah pasar dan pendidikan yang rendah maka cara mereka berbicarapun berbeda dengan orang yang berpendidikan tinggi.

\section{Latar Belakang Pendidikan}


Menurut Sinha dalam Hanum (2012:343) latar belakang pendidikan menjadi salah satu penentu penting intensi kewirausahaan dan kesuksesan usaha yang dijalankan. Latar belakang pendidikan yang baik harus disusun dengan sejelas mungkin dan disertai dengan data atau fakta yang mendukung.

Sedangkan Sedarmayanti (2007:379) dalam Dienul Ihsan (2008) berpendapat bahwa pendidikan adalah suatu proses, teknik, dan metode belajar mengajar dengan maksud mentrasfer suatu pengetahuan diri seseorang kepada orang lain melalui prosedur yang sistematis dan terorganisir.

\section{Pelatihan}

Pelatihan adalah setiap usaha untuk memperbaiki kinerja pada pekerjaan tertentu yang sedang menjadi tanggung jawabnya atau satu pekerjaan yang ada kaitannya dengan pekerjaan (Bernardin dan Rusell dalam Sukoco 2010:77). Dengan semakin meningkatnya persaingan antar perusahaan ataupun organisasi maka pelatihan pada karyawan mutlak dilakukan agar perusahaan dapat terus berkembangan. Selain pelatihan, perusahaan juga membutuhkan pengembangan untuk para karyawannya.

Sedangkan menurut Sedarmayanti (2007:379) dalam Dienul Ihsan (2008) pelatihan adalah suatu proses belajar mengajar dengan menggunakan teknik dan metode tertentu, guna meningkatkan keahlian atau keterampilan seseorang atau sekelompok orang dalam menangani tugas dan fungsi melalui prosedur sistematis dan terorganisir.

Program pelatihan yang menghubungkan dengan visi misi dan strategi perusahaan yang diperlukan pemahaman akan kebutuhan perusahaan dengan mendiagnosa (mengamati) masalah-masalah dan tantangan-tantangan lingkungan yang dihadapi oleh organisasi.

Pelatihan hendaknya memiliki sistem mengumpulan informasi yang memudahkan untuk melihat suatu kinerja karyawan, sehingga lebih mudah untuk menentukan jenis pelatihan yang dibutuhkan oleh karyawan.

\section{Kinerja Karyawan}

Kinerja adalah keluaran yang dihasilkan oleh fungsi-fungsi atau indikator-indikator suatu pekerjaan atau suatu profesi dalam waktu tertentu (Wirawan, 2009:5 dalam Suryoko 2012).

Kinerja merupakan hasil kerja secara kualitas dan kuantitas yang dapat dicapai oleh seorang pegawai dalam melaksanakan tugas sesuai dengan tanggung jawab yang diberikan kepadanya.

Kinerja mengacu pada prestasi karyawan yang diukur berdasarkan standar atau kriteria yang ditetapkan perusahan.

Sedangkan menurut Parlinda, Vera dan Wahyuddin (2004) kinerja karyawan adalah kemampuan kinerja yang dicapai dan diinginkan dari perilaku pegawai dalam melaksanakan dan menyelesaikan tugas-tugas pekerjaan yang menjadi tanggung jawab secara individu atau kelompok.

Penilaian hasil kinerja karyawan merupakan sistem formal untuk menilai dan mengevaluasi kinerja tugas individu atau tim. penilaian kinerja merupakan faktor penting untuk mensukseskan manajemen kinerja (Mondy, 2008:257).

\section{Kredit Komersial}

Kredit adalah penyerahan barang, jasa, atau dari satu pihak atas dasar kepercayaan kepada pihak lain dengan janji membayar dari penerima kredit kepada pemberi pada tanggal yang telah disepakati kedua belah pihak (Vietzhal,2006 dalam Syafitri, 2011:108).

Komersial adalah pinjaman yang diberikan kepada pengusaha, pedagang, atau pegawai yang digunakan untuk modal kerja atau modal usaha dengan jaminan benda bergerak atau benda tidak bergerak (http://www.ksusb.co.id.).

Dapat disimpulkan bahwa kredit komersial adalah kemampuan untuk melaksanakan suatu pembelian atau mengadakan suatu pinjaman dengan suatu 
janji, pembayaran akan dilaksanakan pada jangka waktu yang telah disepakati.

\section{METODE PENELITIAN}

\section{Jenis Penelitian}

Jenis penelitian yang digunakan dalam penelitian ini adalah deskriptif kuantitatif. Untuk melihat pengaruh latar belakang pendidikan dan pelatihan terhadap kinerja karyawan account officer (AO) kredit komersial Bank BRI Sumatera Barat. Menurut Indriantoro dan Supomo (2002) penelitian deskriptif adalah penelitian yang menggambarkan suatu fenomena dengan jalan mendeskripsikan sejumlah variabel yang berkenaan dengan masalah yang diteliti.

\section{Populasi}

Menurut Sugiyono (2009:117) populasi adalah wilayah generalisasi (proses penalaran) yang terdiri atas objek atau subjek yang mempunyai kualitas dan karakteristik tertentu yang diterapkan oleh peneliti untuk pelajari dan kemudian ditarik kesimpulannya.

Jadi populasi bukan hanya orang, tetapi juga objek dan benda-benda alam yang lain. Populasi juga bukan sekedar jumlah yang ada pada objek atau subjek yang dipelajari, tetapi meliputi seluruh karakteristik atau sifat yang dimiliki oleh subjek atau objek itu.

\section{Sampel}

Menurut Sugiyono (2009:118) sampel adalah bagian dari sejumlah dan karakteristik yang memiliki oleh populasi tersebut. Apa yang dipelajari sampel itu, kesimpulannya akan dapat diberlakukan untuk populasi. Untuk itu sampel yang diambil dari populasi harus betul-betul Uji normalitas dilakukan untuk mengetahui data kedua kelompok sampel distribusi normal atau tidak. Jika sampel berdistribusi normal maka populasi juga berdistribusi normal.

\section{Hasil Uji Normalitas}

\begin{tabular}{ccc}
\hline Variabel & Asymsig Alpha & Ket \\
\hline
\end{tabular}

mewakili. Maka sampel dalam peneleitian ini adalah seluruh karyawan Account Officer (AO) Sumatrea Barat.

\section{Sumber Data}

Sumber data yang diperoleh dalam penelitian ini adalah data primer yaitu pada Bank BRI bagian Account Officer (AO) kredit komersial Sumatera Barat.

\section{Definisi Operasional Variabel}

1. Latar Belakang Pendidikan

Fajar Suckoco (2010), Salah satu penentu penting intense kewiraushaan dan kesuksesan usaha yang dijalankan.

2. Pelatihan

Vera Parlinda M. Wahyuddin (2009), Setiap usaha untuk memperbaiki dan meningkatkan kinerja pegawai pada suatu pekerjaan tertentu yang sedang menjadi tanggung jawabnya.

3. Kinerja Karyawan

Vera Parlinda M. Wahyuddin (2009), Kemampuan kinerja yang dicapai dan diiinginkan dari perilaku pegawai dalam melaksanakan dan menelesaikan tugastugas pekerjaan yang menjadi tanggung jawab secara individu atau kelompok.

\section{Teknik Analisis Data \\ Analisis Deskriptif}

Sugiyono (2008:105) analisis deskriptif merupakan analisis penelitian dengan cara mengumpulkan data-data sesuai dengan yang sebenarnya kemudian data-data tersebut disusun, diolah dan dianalisis untuk dapat memberikan gambaran mengenai masalah yang ada.

\section{Analisis Kuantitatif}

\section{a. Uji Asumsi Klasik}

1. Normalitas

\begin{tabular}{cccc}
\hline $\begin{array}{c}\text { Latar } \\
\text { Belakang } \\
\text { Pendidikan }\end{array}$ & 0,010 & 0,05 & Normal \\
$\begin{array}{c}\text { Pelatihan } \\
\text { Kinerja }\end{array}$ & 0,104 & 0,05 & Normal \\
Karyawan & 0,051 & 0,05 & Normal \\
\hline
\end{tabular}

2. Uji Multikoloniearitas 
Uji multikoloniearitas berguna untuk mengetahui apakah pada model regresi yang diajukan telah ditemukan korelasi kuat antar variabel independen. Jika terjadi korelasi kuat, terdapat masalah multikolonieritas yang harus diatasi.

\section{Hasil Uji multikoloniearitas}

\begin{tabular}{cccc}
\hline \multirow{2}{*}{ Model } & \multicolumn{2}{c}{ Colliearity } & \\
\cline { 2 - 3 } & Statistics & Keterangan \\
\hline $\begin{array}{c}\text { Latar } \\
\text { Belakang } \\
\text { Pendidikan } \\
\text { Pelatihan }\end{array}$ & 0,853 & 1,172 & $\begin{array}{c}\text { Tidak terjadi } \\
\text { Multikoloniearitas }\end{array}$ \\
\hline
\end{tabular}

3. Uji Hipotesis

Setelah dilakukan uji normalitas maka dilakukan uji hipotesis untuk mengetahui apakah hipotesis penelitian diterima atau ditolak.

\begin{tabular}{ccccccc}
\hline Model & $\begin{array}{c}\text { Sum of } \\
\text { Squares }\end{array}$ & df & $\begin{array}{c}\text { Mean } \\
\text { Square }\end{array}$ & F & Sig. & Ket \\
\hline Regression & 75.650 & 2 & 37.825 & 6.622 & $0.005^{\text {a }}$ & $\begin{array}{c}\text { Ho di } \\
\text { tolak }\end{array}$ \\
Residual & 154.217 & 27 & 5.712 & & & \\
Total & 229.867 & 29 & & & & \\
\hline
\end{tabular}

\section{Persamaan Regresi Berganda}

\begin{tabular}{|c|c|c|c|c|c|}
\hline \multirow{2}{*}{ Model } & \multicolumn{2}{|c|}{$\begin{array}{l}\text { Unstanderdized } \\
\text { Coefficients }\end{array}$} & \multirow{2}{*}{$\mathrm{t}$} & \multirow{2}{*}{ Sig } & \multirow{2}{*}{ Ket } \\
\hline & B & $\begin{array}{l}\text { Std. } \\
\text { Error }\end{array}$ & & & \\
\hline $\begin{array}{c}\text { (C0nstan } \\
\text { t) }\end{array}$ & 23.465 & 5.242 & 4.477 & 0,000 & \\
\hline $\begin{array}{c}\text { Latar } \\
\text { Belakang } \\
\text { Pendidikan }\end{array}$ & $\begin{array}{c}- \\
0,369\end{array}$ & 0,296 & -1.246 & 0,223 & $\begin{array}{l}\mathrm{H} 0 \mathrm{di} \\
\text { terima }\end{array}$ \\
\hline Pelatihan & 0,365 & 0,136 & 2.681 & 0,012 & $\begin{array}{l}\mathrm{H} 0 \mathrm{di} \\
\text { tolak }\end{array}$ \\
\hline
\end{tabular}

\section{PEMBAHASAN}

Pembahasan hasil penelitian yang dilakukan peneliti berdasarkan hasil analisis deskriptif dan analisis kuantitatif yang telah diuraikan dalam bentuk deskriptif variabel penelitian serta analisis hasil penelitian tentang latar belakang pendidikan dan pelatihan terhadap kinerja karyawan Account Officer (AO).

Berdasarkan hasil deskriptif data dan pengujian hipotesis atasan diketahui bahwa terdapatnya pengaruh yang signifikan antara latar belakang pendidikan terhadap kinerja karyawan Account Officer (AO) Kredit Komersial Bank BRI Sumatera Barat. Besar hbungan bersamasama dapat dilihat dari nilai koefisien determinasi 0,671 artinya $67,1 \%$ kinerja karyawan Account Officer (AO) berhubungan dengan pelatihan dan sisanya $32,9 \%$ artinya pelatihan yang dapat memotivasi karyawan agar dapat memperbaiki kinerjanya.

Data Latar belakang pendidikan (Variabel $\mathrm{X}_{1}$ ) diperoleh melalui pengisian kuesioner penelitian berupa butir-butir soal yang diberikan kepada karyawan Bank BRI Sumatera Barat sebagai responden. Berdasarkan data yang terkumpul, dihasilkan skor terendah 68,00 dan skor tertinggi 68,50 , skor rata-rata $(\mathrm{X})$ sebesar 68,25 .

Selanjutnya, berdasarkan perhitungan dari kinerja karyawan Account Officer (AO) (Variabel Y) yang diperoleh melalui Skala Likert oleh 30 karyawan Account Officer (AO) Bank BRI Sumatera Barata sebagai responden. Berdasarkan data yang terkumpul, dihasilkan skor terendah 88 dan skor tertinggi 143. skor rata-rata (Y) sebesar 4,77.

Berdasarkan hasil perhitungan statistik dan hasil analisis data di atas, dapat dinyatakan bahwa terdapat hubungan positif antara latar belakang pendidikan dengan kinerja karyawan Account Officer (AO). Dapat dikatakan terdapat hubungan positif yang signifikan antara latar belakang pendidikan dengan kinerja karyawan Account Officer (AO). Besarnya derajat hubungan kedua variabel dapat dilihat dari besarnya angka koefisien determinasi yaitu $67,1 \%$.

\section{PENUTUP \\ Kesimpulan}


Berdasarkan hasil penelitian yang diperoleh, maka peneliti dapat mengambil kesimpulan tiap-tiap kota sebagai berikut:

1. Dari hasil analisis data dan pengujian hipotesis pertama yang dilakukan diketahui bahwa tidak terdapat hubungan yang signifikan antara latar belakang pendidikan terhadap kinerja karyawan Acoount Officer (AO). Dari analisis yang diperoleh nilai sig sebesar $0,223>$ 0,05 dan $\mathrm{t}_{\text {hitung }}-1,246<\mathrm{t}_{\text {tabel }} 1,697$. Maka dapat disimpulkan bahwa latar belakang pendidikan yang dimiliki karyawan tidak berhubungan baik atau tiadaknya kinerja yang akan didapatkan oleh karyawan Account Officer (AO).

2. Dari hasil analisis data dan pengujian hipotesis yang dilakukan diketahui bahwa terdapat hubungan signifikan antara pelatihan terhadap kinerja karyawan Account Officer (AO), dengan nilai sig sebesar $0,012<0,05$ dan $t_{\text {hitung }} 2,681>t_{\text {tabel }}$ 1,697. Maka dapat disimpulkan bahwa pelatihan yang iikuti karyawan dikuti dengan baik sehingga karyawan dapat belajar langsung kelapangan dan tidak selamanya kinerja karyawan kurang baik.

\section{Saran}

Sesuai dengan hasil penelitian yang diperoleh maka peneliti mengemukakan beberapa saran sebagai berikut:

1. Bagi peneliti, kinerja karyawan merupakan hal paling utama dalam melukakan pekerjaan agar mendapatkan hasil yang baik.

2. Bagi perusahaan, hendaknya penelitian ini dapat memberikan motivasi bagi perusahaan untuk meningkatkan kinerja karyawan yang lebih baik.

\section{DAFTAR PUSTAKA}

10.22202/economica.2013.v2.i1.2128

Bank BRI.(2009)."Bahan Ajar Account Officer (AO)"..Pusat Pendidikan dan Pelatihan. Jakarta

Dienul,Ihsan.(2008)."Pengaruh

Pendidikan dan Pelatihan Terhadap

Kinerja Karyawan Pada PT. Pusri

Perkapalan dan Pengantongan

Palembang". Skripsi

Hanum.(2012)"Pengaruh latar Belakang Pendidikan Terhadap Motivasi

Kewirausahaan Mahasiswa".Jurnal

Seminar Hasil-Hasil

Penelitian.Universitas

muhammadiyah.Semarang.

Mondy,R.Wayne.(2008). "Manajemen

Sumber Daya Manusia". Jakarta:Erlangga

Syafitri.(2011)."Faktor-faktor yang

Mempengaruhi Kualitas Kredit

dalam Dunia Perbankan".Jurnal

Manajemen dan

Kewirausahaan.Diakses 23 Maret

2013.

Sugiyono.(2009)."Metodologi Penelitian

Pendidikan ". Bandung:Alfabet.

----------.(2008)."Metode Penelitian

Kuantitatif Kualitatif dan

$R \& D$ ”. Bandung Alfabeta.

Sukoco. (2010)."Pengaruh Pendidikan

Dan Pelatihan, Pembelajaran

Organisasi Terhadap Kinerja

Dengan Kompetensi Sebagai

Mediasi".Jurnal Bisnis Dan

Ekonomi.Universitas

Stikubank.Semarang

Suliyanto.(2011). "Ekonomitrika

Terapan”.Yogyakarta:Hak Cipta.

Vera Parlinda dan M. Wahyudi. (2004)."Pengaruh Kepemimpinan, Motivasi, Pelatihan dan Lingkungan Kerja Terhadap Kinerja Karyawan Pada Perusahaan Daerah Air Minum Kota

Surakarta".JurnalDayaSaing,Vol.6, No.2. 